\title{
Alpha-1-antitrypsin and the liver: a routine immunohistological screen
}

\author{
JM THEAKER, KA FLEMING \\ From the University of Oxford, Nuffield Department of Pathology, John Radcliffe Hospital, Oxford
}

SUMMARY One hundred and eighty five consecutive liver biopsies were immunostained using anti-alpha-1-antitrypsin to assess the use of routine immunohistochemistry in the diagnosis of alpha-1-antitrypsin (AAT) deficiency. About half the livers showed staining of hepatocytes for alpha-1-antitrypsin, but most of these livers showed a panlobular pattern, possibly indicating increased synthesis of AAT. Only ten contained periportal granules, said to be typical of AAT deficiency. In cases in which serum was also available for quantitation and phenotyping there was no absolute relation between staining pattern, phenotype, and serum concentrations: the immunohistological screening technique, therefore, has limitations in the diagnosis of AAT deficiency in liver biopsy specimens.

Alpha-1-antitrypsin (AAT) is the principal serum antiprotease and is mainly synthesised in the liver. ${ }^{1}$ There are at least 30 alleles for its gene, ${ }^{1}$ and there is extensive evidence that some phenotypes are associated with certain diseases, including emphysema, ${ }^{2}$ cirrhosis, ${ }^{34}$ and neonatal hepatitis. ${ }^{2}$ Such phenotypes usually result in low serum concentrations of detectable AAT, and, therefore, the term AAT deficiency (AAD) is used to describe them. The most common phenotype is designated PiM (Protease inhibitor $\mathbf{M}$ ) and the most common allele associated with deficiency is $Z$.

Identifying this deficiency is important, partly as it is an inherited condition and partly as it must be differentiated from other diseases which cause similar changes to the tissue. Unfortunately, the diagnosis of the heterozygous state cannot be reliably made by measuring serum concentrations: AAT is an acute phase reactant and concentrations in such genetically deficient people can be raised into the normal range. ${ }^{35}$ Phenotyping entails the use of techniques that are unavailable in most diagnostic laboratories, and, therefore, an easy and reliable method of detecting disease related phenotypes is required.

Early reports suggested that a characteristic histological feature of patients with AAT deficiency was PAS positive and diastase resistant (PAS-D) granules within the cytoplasm of periportal hepatocytes, ${ }^{2}$ which also reacted immunohisto-

Accepted for publication 17 September 1985 logically with antisera to AAT. Further studies reinforced this finding and showed a close correlation between the presence of the PAS-D granules and the $\mathrm{Z}$ gene. ${ }^{6-8}$ Thus it was hoped that the presence of these granules would be a simple and reliable $\frac{\mathbb{D}}{\mathbb{D}}$ indicator of the $\mathrm{Z}$ gene, and, therefore, most cases of $\propto$ AAT deficiency. Subsequently, however, occasional $\overrightarrow{\hat{O}}$ reports have shown that periportal hepatocytes of 3 PiM (normal) patients can contain similar PAS-D positive granules, which do not stain as AAT immunohistologically. ${ }^{89}$ There are also patients with the $\mathrm{Z}$ gene whose periportal hepatocytes do not contain PAS-D granules, although they can contain 3 AAT positive granules on immunohistological staining. ${ }^{10}$ These results, therefore, suggest that, in the absence of phenotyping, a better indicator of the AAD phenotype may be to show the presence of AAT granules in periportal hepatocytes by immunohistochemistry.

To assess the advantages and disadvantages of this $\widetilde{N}$ approach we report the results of a routine screen of $N$ unselected liver biopsy specimens for AAT granules $\stackrel{\sim}{\mathrm{\omega}}$ by immunohistological means and compare these results with the serum AAT concentrations and the patient's phenotype.

\section{Material and methods}

One hundred and eighty five liver biopsies (most of $\frac{0}{\mathbb{D}}$ which were needle biopsies) were received $\stackrel{\odot}{\mathbb{D}}$ consecutively in the Nuffield department of pathology $\varrho$ at this hospital. They were routinely fixed in $10 \%$ 
formol saline and processed to paraffin. Sections were stained with haematoxylin and eosin and by the periodic acid Schiff technique after diastase digestion. Immunohistological staining for AAT was performed by an indirect immunoperoxidase method as described, ${ }^{11}$ using antiserum to human AAT from Behringwerke at a dilution of $1 / 100$. The specificity of the antiserum was tested both by Ouchterlony gel diffusion and immunoelectrophoresis against normal human serum and purified AAT (Sigma). These procedures showed only a single precipitin line with similar electrophoretic mobilities and a reaction of identity between the purified AAT and normal human serum. Specificity of staining was tested by preabsorbing the antibody with AAT. This completely abolished all immunohistological staining (result not shown).

As further controls the anti-AAT was replaced by antisera to hepatitis B surface antigen (Dakopatts), or human chorionic gonadotrophin, or by the second antibody (peroxidase coupled swine antirabbit) alone. All these controls were negative.

The serum AAT concentrations were measured by automated nephelometry (Beckman ICS system) in the department of immunology at this hospital, and phenotyping was performed by isoelectric focusing on polyacrylamide gels at the Medical Research Council's human biochemical genetics unit, London.

\section{Results}

There were four immunohistological staining patterns of hepatocytes: (a) negative; (b) a periportal granular staining, as described in $\mathrm{AAD}^{2}$ (Figs 1 and 2); (c) a diffuse, finely granular, cytoplasmic staining of hepatocytes scattered focally throughout the liver lobule (we called this pattern panlobular, diffuse (Figs 3 and 4). The intensity of staining varied considerably between hepatocytes within a single biopsy. Occasional individual hepatocytes stained intensely and some groups of hepatocytes stained more lightly, and the rest of the hepatocytes showed a very faint positivity); (d) a coarse granular staining of hepatocytes with a similar distribution as the above. We called this panlobular, coarse (Fig. 5).

Although, in general, the distribution between patterns was clear, occasionally, that between the third and fourth patterns of staining was blurred. In addition, when only few hepatocytes stained, which happened rarely, the distinction between periportal and panlobular coarse staining was difficult to make.

Table 1 shows the incidence of each staining pattern in various diseases. About half the livers yielded positive results. Most of the positive livers showed a panlobular pattern. The only disease associated with this pattern was large duct obstruction, which nearly all the cases showed ( 20 of 22). Ten of 185 cases showed periportal AAT granules (apparently typical of AAT deficiency), four of which were cirrhotic, the other diagnoses being metastatic carcinoma, large duct obstruction, fatty liver, and normality.

Table 2 shows the mean serum AAT concentrations compared with the immunohistological pattern for the 66 cases in which serum was available for quantification. Although there was a considerable overlap in the serum concentrations of AAT in all groups, those patients with panlobular positivity had the highest values. The patients with periportal granules had the lowest values, which was consistent with AAT deficiency. Two of these patients, however, had high values and this raised the mean concentration into the normal range.

Of the 41 sera phenotyped, four were either homozygous or heterozygous for the $\mathrm{Z}$ gene (Table 3). Two of these showed the periportal granular pattern typical of AAT deficiency, but two showed the panlobular diffuse pattern. (The serum concentrations of the panlobular pattern were 242 and $253 \mathrm{mg} / \mathrm{dl}$ ). By contrast, the two cases with periportal granules were phenotyped as PiM (serum concentrations 270 and $274 \mathrm{mg} / \mathrm{dl}$, respectively).

\section{Discussion}

This study aimed to assess the usefulness (for diagnosing AAT deficiency) of a routine immunohistological screen of liver biopsies for the presence of periportal AAT granules. We found that about half of the livers examined contained detectable AAT. There were three different patterns, however, panlobular diffuse, panlobular coarse, and periportal granules.

Most cases showed one or other of the first two patterns. These patterns were not associated with any particular AAT phenotype, but they were strongly associated with large duct obstruction. As AAT is present in bile ${ }^{12}$ this may reflect obstruction of an excretion route. Interestingly, however, other cases showing cholestasis-primary biliary cirrhosis for example-did not show this preponderance of panlobular staining.

On assessment of the morphological similarities and the serum AAT concentrations, the panlobular diffuse and coarse patterns probably represented variants of the same process, the coarse pattern being the more severe. These panlobular patterns may also reflect increased AAT synthesis as part of an acute phase reaction as, although not statistically significant, there was a higher mean serum AAT value in these two groups compared with the cases in which hepatocytes were negative. Although this panlobular 


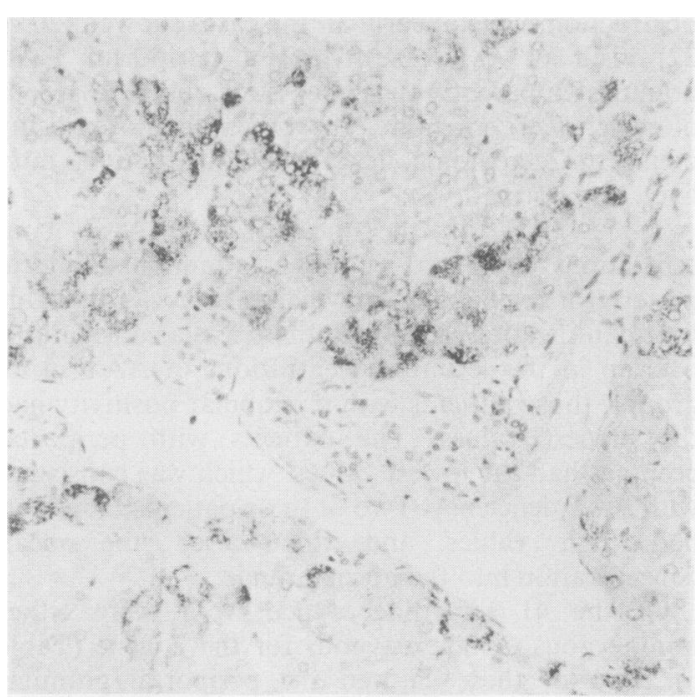

Fig. 1 Periportal granular pattern. Many periportal hepatocytes contain discrete granular inclusions. (Immunoperoxidase.) $\times 45$.

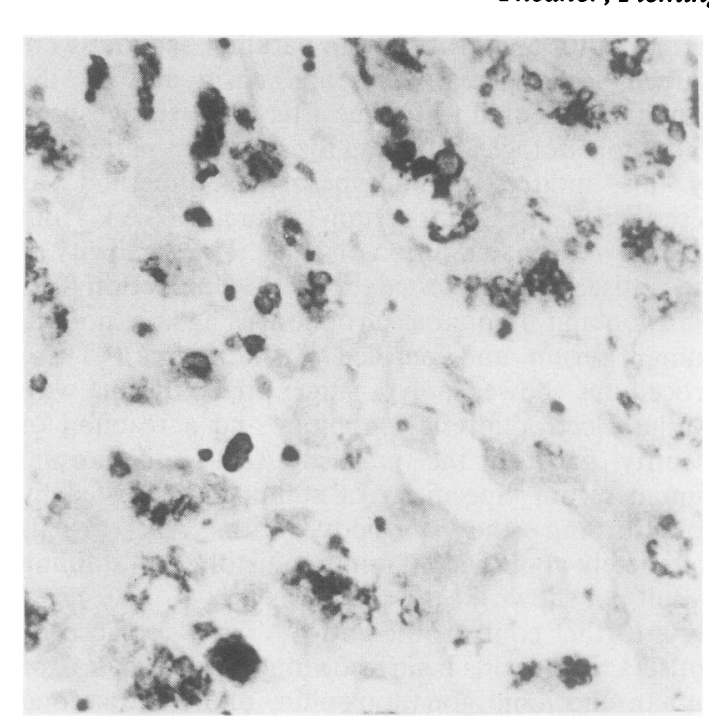

Fig. 2 Periportal granular pattern. Higher power of Fig. 1 . (Immunoperoxidase.) $\times 350$.

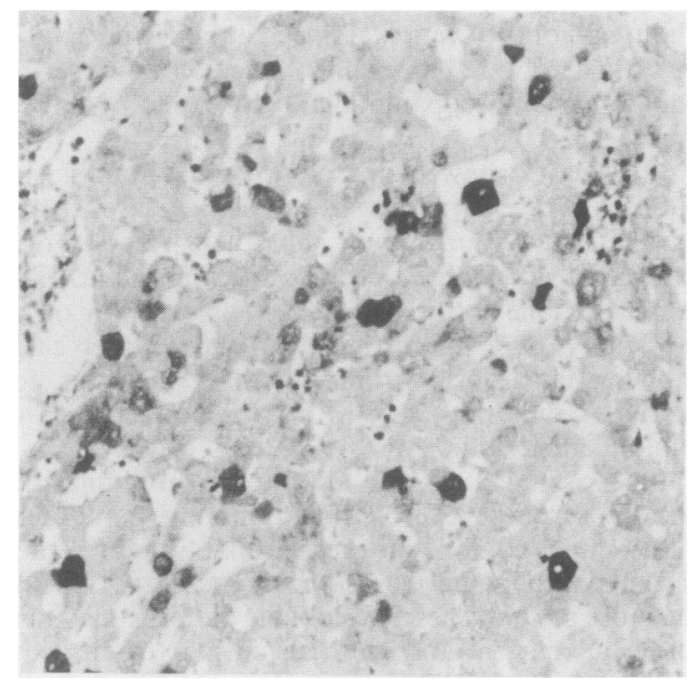

Fig. 3 Panlobular diffuse pattern. Occasional hepatocytes diffusely scattered throughout lobule show finely granular cytoplasmic staining of variable intensity. (Immunoperoxidase.) $\times 65$.



Fig. 4 Higher power field of Fig. 3 to shows diffuse cytoplasmic staining. Note also positive Kupffer cells. (Immunoperoxidase.) $\times 400$. 


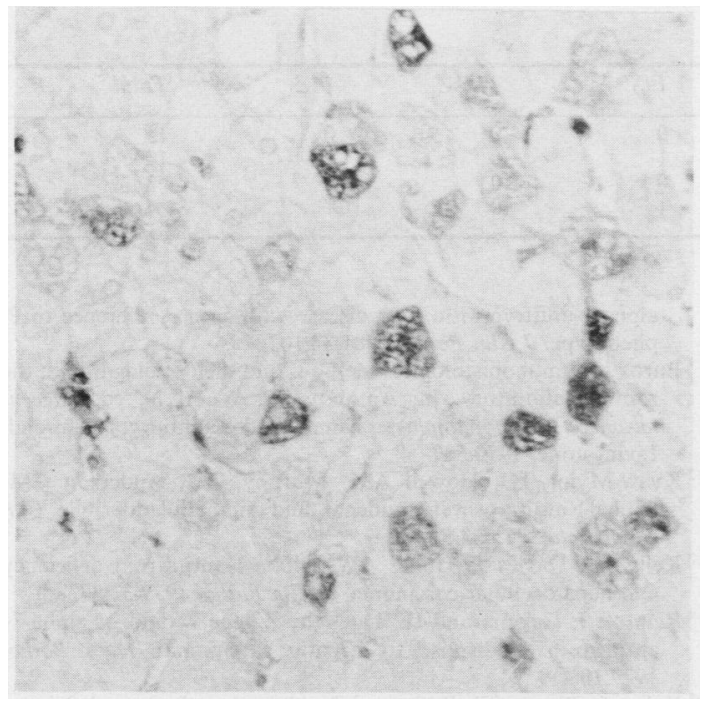

Fig. 5 Panlobular coarse pattern. Occasional hepatocytes throughout lobule show coarse granular positivity. (Immunoperoxidase.) $\times 200$.

staining pattern has occasionally been noted in the course of investigations into other aspects of AAD, ${ }^{1013-15}$ the incidence has varied greatly $(11-57 \%)$. This presumably reflects varying sensitivities in the immunohistological techniques used and heterogeneity of the cases studied.

The third and quite separate pattern of staining observed was that of AAT granules in periportal hepatocytes. This pattern is usually considered to indicate the presence of an AAT deficiency phenotype. $^{2}$ Although these cases tended to have lower serum AAT concentrations than the other patterns, two patients with typical AAT granules had greater than normal serum AAT values and normal phenotypes (PiM). Other workers have also reported cases in which periportal AAT granules were detected immunohistologically in the absence of the $\mathrm{Z}$
Table 2 AAT staining pattern and serum concentration (normal range $107-209 \mathrm{mg} / \mathrm{dl}$ )

\begin{tabular}{lll}
\hline Pattern & No of cases & Mean $(S D)(\mathrm{mg} / \mathrm{dl})$ \\
\hline Negative & 22 & $228(87)$ \\
Panlobular diffuse & 31 & $267(109)$ \\
Panlobular coarse & 7 & $269(25)$ \\
Periportal granules & 6 & $163(68)$ \\
\hline
\end{tabular}

gene. ${ }^{1016-18}$ In addition, we found two patients homozygous for the $\mathrm{Z}$ gene, but without typical periportal AAT granules and with greater than normal serum AAT values.

The discrepancy in this study between the presence of hepatocyte AAT and the $Z$ phenotype is greater than that previously reported using PAS-D screening. Errors in the interpretation of the staining patterns or in phenotyping probably do not account for this, as, in general, the distinction between staining patterns was quite clear and the phenotyping was performed by a reference laboratory. A more likely explanation is that immunohistochemistry is more sensitive than PAS-D staining, and, therefore, we detected greater numbers of positive hepatocytes than is possible with the PAS-D technique. Thus by using this technique routinely on all biopsies (not just those with PAS-D granules), we were able to detect increased numbers of those cases lacking a correlation between periportal AAT granules and the $\mathrm{Z}$ gene.

In summary, it seems that there is no absolute direct correlation between the serum AAT value, the Pi phenotype, and the presence or absence of immunoreactive periportal AAT granules. Accordingly, simple reliance on immunohistological detection of AAT in hepatocytes cannot be used as a diagnostic indicator of deficiency, and thus there is no advantage in routinely immunoscreening liver biopsy specimens for AAT. Recent technical advances such as the production of monoclonal antibodies against the $\mathrm{Z}$ protein variant $^{19}$ and DNA hybridisation ${ }^{20}$ may lead to a greater understanding and a more reliable diagnosis of this poorly understood disorder.

Table 1 AAT staining pattern and histological diagnosis

\begin{tabular}{|c|c|c|c|c|c|}
\hline Diagnosis & Negative & Panlobular diffuse & Panlobular coarse & Periportal granules & Total \\
\hline $\begin{array}{l}\text { Normal appearance } \\
\text { Alcoholic hepatitis } \\
\text { Cirrhosis: }\end{array}$ & $\begin{array}{r}15 \\
7\end{array}$ & $\begin{array}{l}5 \\
5\end{array}$ & $\begin{array}{l}\mathbf{0} \\
\mathbf{0}\end{array}$ & $\begin{array}{l}1 \\
0\end{array}$ & $\begin{array}{l}21 \\
12\end{array}$ \\
\hline $\begin{array}{l}\text { Alcoholic } \\
\text { Other causes } \\
\text { Fatty liver } \\
\text { Large duct obstruction } \\
\text { Pimary biliary cirrhosis } \\
\text { Metastatic carcinoma } \\
\text { Non-specific reactive hepatitis } \\
\text { Others }\end{array}$ & $\begin{array}{r}10 \\
3 \\
12 \\
1 \\
4 \\
16 \\
9 \\
15\end{array}$ & $\begin{array}{r}5 \\
5 \\
7 \\
18 \\
5 \\
5 \\
6 \\
11\end{array}$ & $\begin{array}{l}0 \\
1 \\
0 \\
2 \\
1 \\
4 \\
0 \\
3\end{array}$ & $\begin{array}{l}1 \\
3 \\
2 \\
1 \\
0 \\
2 \\
0 \\
0\end{array}$ & $\begin{array}{l}16 \\
12 \\
21 \\
22 \\
10 \\
27 \\
15 \\
29\end{array}$ \\
\hline Total & 92 & 72 & 11 & 10 & 185 \\
\hline
\end{tabular}


Table 3 AAT staining pattern and phenotype

\begin{tabular}{|c|c|c|c|c|c|c|}
\hline Pattern & $P i M$ & PiMS & $P i S$ & PiMZ & $P i Z$ & Total \\
\hline $\begin{array}{l}\text { Negative } \\
\text { Panlobular diffuse } \\
\text { Panlobular coarse } \\
\text { Periportal granules }\end{array}$ & $\begin{array}{r}11 \\
13 \\
3 \\
2\end{array}$ & $\begin{array}{l}4 \\
3 \\
0 \\
0\end{array}$ & $\begin{array}{l}0 \\
1 \\
0 \\
1\end{array}$ & $\begin{array}{l}\mathbf{0} \\
\mathbf{0} \\
\mathbf{0} \\
\mathbf{0}\end{array}$ & $\begin{array}{l}0 \\
2 \\
0 \\
1\end{array}$ & $\begin{array}{r}15 \\
19 \\
3 \\
4\end{array}$ \\
\hline
\end{tabular}

We thank Dr DA Hopkinson of the Medical Research Council human biochemical genetics unit, Galton Laboratory, University College, for phenotyping these samples and Dr HM Chapel of the immunology department, John Radcliffe Hospital, for determining the serum values.

\section{References}

${ }^{1}$ Mowat AP. Alpha-1-antitrypsin deficiency in liver disease. In: Williams R, Maddrey WC, eds. Liver. London: Butterworths, 1984:52-75.

${ }^{2}$ Sharp HL. Alpha-1-antitrypsin deficiency. Hosp Pract 1971;6:83-96.

${ }^{3}$ Hodges JR, Millward-Sadler GH, Barbatis C, Wright R. Heterozygous MZ Alpha-1-antitrypsin deficiency in adults with chronic active hepatitis and cryptogenic cirrhosis. New Engl J Med 1981;304:557-60.

${ }^{4}$ Triger DR, Millward-Sadler GH, Czaykowski AA, Trowell J, Wright R. Alpha-1-antitrypsin deficiency and liver disease in adults. $Q J$ Med 1976;45:351-72.

${ }^{5}$ Talamo RC, Langley CE, Levine BW, Kazemi H. Genetics vs. quantitative analysis of serum alpha-1-antitrypsin. New Engl J Med 1972;287:1067-9.

${ }^{6}$ Gordon HW, Dixon J, Rogers JC, Mittman C, Lieberman J. Alpha1-antitrypsin $\left(A_{1}\right.$ AT) accumulation in livers of emphysematous patients with $A_{1}$ AT deficiency. Hum Pathol 1972;3:361.

${ }^{7}$ Lieberman J, Mittman C, Gordon HW. Alpha-1-antitrypsin in the livers of patients with emphysema. Science 1972;175:63.

${ }^{8}$ Millward-Sadler GH, Czaykowski AA, Wright R. Diagnosis of Alpha-1-antitrypsin deficiency. Lancet 1975;ii:1050.

${ }^{9}$ Pariente E-A, Degott C, Martin J-P, Feldmann G, Potet F, Benhamou J-P. Hepatocytic PAS-positive diastase-resistant inclusions in the absence of alpha-1-antitrypsin deficiency-high prevalence in alcoholic cirrhosis. Am J Clin Pathol 1981; 76:299-302.

${ }^{10}$ Carlson J, Eriksson S, Hagerstrand I. Intra- and extracellular alpha-1-antitrypsin in liver disease with special reference to $P i$ phenotype. J Clin Pathol 1981;34:1020-5.

${ }^{11}$ Burns J. Immunohistological methods and their application in the routine laboratory. In: Anthony PP, Woolf N, eds. Recent advances in histopathology. Number 10. Edinburgh: Churchil Livingstone, 1970:337-50.

${ }^{12}$ Kyaw-Myint TO, Howell AM, Murphy GM, Anderson CM. Alpha-1-antitrypsin in duodenal fluid and gallbladder bile. Clin Chim Acta 1975;59:51-4.

${ }^{13}$ Kelly JK, Davies JS, Jones AW. Alpha-1-antitrypsin deficiency is and hepatocellular carcinoma. J Clin Pathol 1979;32:373-6.

${ }^{14}$ Reintoft I, Hagerstrand IE. Does the $Z$ gene variant of alpha-1- 은 antitrypsin predispose to hepatic carcinoma? Hum Pathol 1979;10:419-24.

${ }^{15}$ Cohen C, Berson SD, Budgeon LR. Alpha-1-antitrypsin deficiency in Southern African hepatocellular carcinoma patients: an immunoperoxidase and histochemical study. Cancer 1982;49:2537-40

${ }^{16}$ Kelly JK, Taylor TV, Milford-Ward A. Alpha-1-antitrypsin PiS $\vec{\bullet}$ phenotype and inclusion bodies in alcoholic hepatitis. $J$ Clin Pathol 1979;32:706-9.

${ }^{17}$ Fischer RL, Taylor L, Sherlock S. Alpha-1-antitrypsin deficiency in liver disease and extent of the problem. Gastroenterology 1976;71:646-51.

${ }^{18}$ Bradfield JWB, Blenkinsopp WK. Alpha-1-antitrypsin globules in the liver and PiM phenotype. J Clin Pathol 1977;30:464-6.

${ }^{19}$ Wallmark A, Alm R, Eriksson S. Monoclonal antibody specific for the mutant PiZ alpha-1-antitrypsin and its application in an ELISA procedure for identification of $\mathrm{PiZ}$ gene carriers. Proc Natl Acad Sci USA 1984;81:5690-3.

${ }^{20}$ Kidd VJ, Golbus MS, Wallace RB, Itakura K, Woo SLC. Prenatal diagnosis of alpha-1-antitrypsin deficiency by direct analysis of the mutation site in the gene. New Engl J Med 1984;310:639-42.

Requests for reprints to: $\operatorname{Dr}$ KA Fleming, Nuffield Department of Pathology, John Radcliffe Hospital, Headington, Oxford OX3 9DU, England. 